\title{
Onboard measurement system of atmospheric carbon monoxide in the Pacific by voluntary observing ships
}

\author{
H. Nara, H. Tanimoto, Y. Nojiri, H. Mukai, T. Machida, and Y. Tohjima \\ National Institute for Environmental Studies, 16-2 Onogawa, Tsukuba, Ibaraki, 305-8506, Japan \\ Received: 28 June 2011 - Published in Atmos. Meas. Tech. Discuss.: 18 July 2011 \\ Revised: 4 October 2011 - Accepted: 11 November 2011 - Published: 24 November 2011
}

\begin{abstract}
Long-term monitoring of carbon monoxide (CO) mixing ratios in the atmosphere over the Pacific Ocean is being carried out on commercial cargo vessels participating in the National Institute for Environmental Studies Voluntary Observing Ships program. The program provides a regular platform for measurement of atmospheric $\mathrm{CO}$ along four cruise routes: from Japan to Oceania, the United States, Canada, and Southeast Asia. Flask samples are collected during every cruise for subsequent analysis in the laboratory, and in 2005, continuous shipboard CO measurements were initiated on three of the routes. Here, we describe the system we developed for onboard measurement of CO mixing ratios with a commercially available gas filter correlation $\mathrm{CO}$ analyzer. The fully automated system measures $\mathrm{CO}$ in ambient air, and the detector sensitivity and background signals are calibrated by referencing the measurements to a $\mathrm{CO}$ in-air standard gas $(\sim 1 \mathrm{ppmv})$ and to CO-free air scrubbed with a catalyst, respectively. We examined the artificial production of $\mathrm{CO}$ in the high-pressure working gas standards during storage by referencing the measurements to $\mathrm{CO}$ standard gases maintained as our primary scale before and after use on the ships. The onboard performance of the continuous $\mathrm{CO}$ measurement system was evaluated by comparing its data with data from laboratory analyses of flask samples using gas chromatography with a reduction gas detector. The reasonably good consistency between the two independent measurement methods demonstrated the good performance of both methods over the course of 3-5 years. The continuous measurement system was more useful than the flask sampling method for regionally polluted air masses, which were often encountered on Southeast Asian cruises.
\end{abstract}

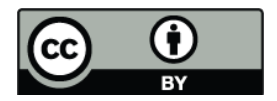

Correspondence to: $\mathrm{H}$. Tanimoto (tanimoto@nies.go.jp)

\section{Introduction}

Atmospheric carbon monoxide $(\mathrm{CO})$ is an important trace gas in the tropospheric photochemistry. Because most of the hydroxyl $(\mathrm{OH})$ radicals in the troposphere are consumed by reaction with $\mathrm{CO}, \mathrm{CO}$ influences the distribution of other reduced trace gases such as methane by changing the oxidation capacity of the atmosphere (Logan et al., 1981). Although CO is naturally produced by oxidation of hydrocarbons in the atmosphere, fossil fuel combustion and biomass burning account for a large portion of surface $\mathrm{CO}$ emissions. The atmospheric distribution of $\mathrm{CO}$ is determined mainly by the locations of emission sources and by subsequent longrange transport of air masses containing $\mathrm{CO}$, because of its relatively long lifetime, typically $\sim 2$ months in the troposphere. These two factors result in complexity in the temporal and spatial variations of $\mathrm{CO}$ on a global scale (Novelli et al., 1998a). Therefore, additional observational evidence is needed for a better understanding of the factors affecting temporal and spatial variations of $\mathrm{CO}$ and its effect on the oxidation capacity of the atmosphere.

To improve our understanding concerning the global distributions of $\mathrm{CO}$, investigators have made stationary, shipboard, airborne, and satellite observations of $\mathrm{CO}$ during the past decades. For example, Novelli et al. (1998a, 2003) used a global air-sampling network of 49 surface stations established by the National Oceanic and Atmospheric Administration (NOAA) Earth System Research Laboratory's Global Monitoring Division (GMD) to capture the global distribution of $\mathrm{CO}$ and long-term trends in $\mathrm{CO}$ mixing ratios in the lower troposphere. Yashiro et al. (2009) made shipboard observations of $\mathrm{CO}$ on the basis of flask sampling in the western Pacific, reporting long-term trend and variability of $\mathrm{CO}$ between Japan-Australia/New Zealand and between JapanUnited States from 1990 to 2006 . Several observation programs made atmospheric observation using civil aircraft over

Published by Copernicus Publications on behalf of the European Geosciences Union. 
a wide area in the upper troposphere and the lower stratosphere. Matsueda et al. (1998) reported flask sampling observations of $\mathrm{CO}$ in the upper troposphere over the western Pacific since 1993 using a passenger aircraft between Australia and Japan. Nedelec et al. (2003) reported aircraft observations of CO made starting in 1997 as a part of the Measurements of Ozone, Water Vapour, Carbon Monoxide and Nitrogen Oxides by In-Service Airbus Aircraft (MOZAIC) program, customizing a commercially available infrared analyzer to obtain continuous, high-precision measurements. Brenninkmeijer et al. (1999) started the Civil Aircraft for Regular Investigation of the Atmosphere Based on an Instrument Container (CARIBIC) program in 1997. This program is based on an airfreight container equipped with automated in situ measurement instruments and sampling devices for observing more than 60 different trace gases and aerosol properties, and $\mathrm{CO}$ is continuously measured by a vacuum ultraviolet spectrometer (Brenninkmeijer et al., 2007).

Satellite observation can provide global pictures of $\mathrm{CO}$ distributions on a monthly or even daily basis. On the basis of Measurements of Pollution in the Troposphere (MOPITT) observations, Yurganov et al. (2005) reported an increase in the total column abundance of $\mathrm{CO}$ in the summer and autumn of 2002 and 2003 over boreal regions in the Northern Hemisphere. Tanimoto et al. (2008a) diagnosed consistency between MOPITT observations and emission estimates of $\mathrm{CO}$ from East Asia for the period from 2000 to 2006. Observations made by the Atmospheric Infrared Sounder (AIRS) demonstrated its ability to track long-range transport of $\mathrm{CO}$ from emission sources (Yurganov et al., 2008; Tanimoto et al., 2009a). However, determination of absolute CO mixing ratios by means of satellites is challenging, and information on the vertical profiles and structures is often limited (Warner et al., 2007; Yurganov et al., 2008). Thus satellite observations of $\mathrm{CO}$ still need to be supported and validated by in situ observations.

Uncertainties in the global $\mathrm{CO}$ distribution remain large because past observations tended to be sporadic and localized. Moreover, interannual variations and long-term trends of $\mathrm{CO}$ are often ambiguous owing to difficulties in measuring $\mathrm{CO}$ precisely and accurately. For example, most groundbased measurements of $\mathrm{CO}$ have been made by means of gas chromatography with reduced gas detection (GC/RGD), gas filter correlation (GFC)/nondispersive infrared absorption analysis, or a vacuum ultraviolet resonance fluorescence VURF (e.g. Parrish et al., 1994; Gerbig et al., 1996, 1999; Novelli et al., 1998b; Tanimoto et al., 2000, 2009b; Takegawa et al., 2001; Nedelec et al., 2003; Sawa et al., 2007). The resulting data often show differences originating from differences between the measurement techniques and calibration scales (Novelli et al., 1991, 1998a; Tanimoto et al., 2007; Ou-Yang et al., 2009; Zellweger et al., 2009). Novelli et al. (1998b) compared data obtained by eleven laboratories as a part of the program for validation of the Measurement of Air Pollution from Satellites (MAPS) instrument and found significant differences among several laboratories, even among laboratories using similar methods and a common standard gas. Maintenance of $\mathrm{CO}$ gas standards is often plagued by drift of the $\mathrm{CO}$ mixing ratios in high-pressure gas cylinders, particularly at ppbv levels (Novelli et al., 1991, 1994, 2003). Although the drift rate of CO mixing ratios is only a few ppbv per year (compared to the few tens to hundreds of ppbv $\mathrm{CO}$ at which the standards are prepared), the drift substantially affects derivation of long-term trends and interannual variability of CO (Zander et al., 1989; Brunke et al., 1990; Novelli et al., 2003; Zellweger et al., 2009). Furthermore, the drift substantially affects the calibration scales maintained for long-term atmospheric monitoring programs. For these reasons, obtaining accurate measurements of $\mathrm{CO}$ is still a challenge, which highlights the need for rigorous control of the accuracy and precision of $\mathrm{CO}$ instrumentation and calibration scales.

In March 1992, the National Institute for Environmental Studies (NIES) began observing atmospheric CO by means of flask sampling followed by laboratory analysis. In November 2005, NIES started continuous observations of $\mathrm{CO}$, to better understand $\mathrm{CO}$ distributions over the Pacific Ocean and to examine the possible influences of rapidly increasing human activity in this region. Here we present a new system for continuously measuring $\mathrm{CO}$, together with quality assessment and quality control results for $\mathrm{CO}$ data obtained over the course of 5 years.

\section{NIES Voluntary Observing Ships program for long-term atmospheric monitoring}

Since 1992, NIES has been operating a long-term program for monitoring trace gases of atmospheric importance in the background air over the Pacific Ocean. The NIES Voluntary Observing Ships (NIES VOS) program makes use of commercial cargo vessels because they operate regularly over fixed routes for long periods and sail over a wide area between various ports. This program allows systematic and continuous measurements of trace gases, providing long-term datasets for background air in the Pacific region, spanning wide latitudinal zones in both hemispheres. Figure 1 shows the current spatial coverage of atmospheric observations operated in the NIES VOS program. In collaboration with maritime shipping companies, present observations have been made onboard motor vessels (M/V) Fujitrans World (FTW; owned by Kagoshima Shipping Co., Japan), Pyxis (PX; owned by Toyofuji Shipping Co., Japan), Skaubryn (SKB; owned by Seaboard International Shipping Co., Canada), and Trans Future 5 (TF5; owned by Toyofuji Shipping Co., Japan) since September 2007, November 2001, June 2007, and November 2005, respectively. These ships sail between Japan and Southeast Asian countries (Southeast Asia route, 4-week interval), between Japan and the United States (North America route, 9-week 


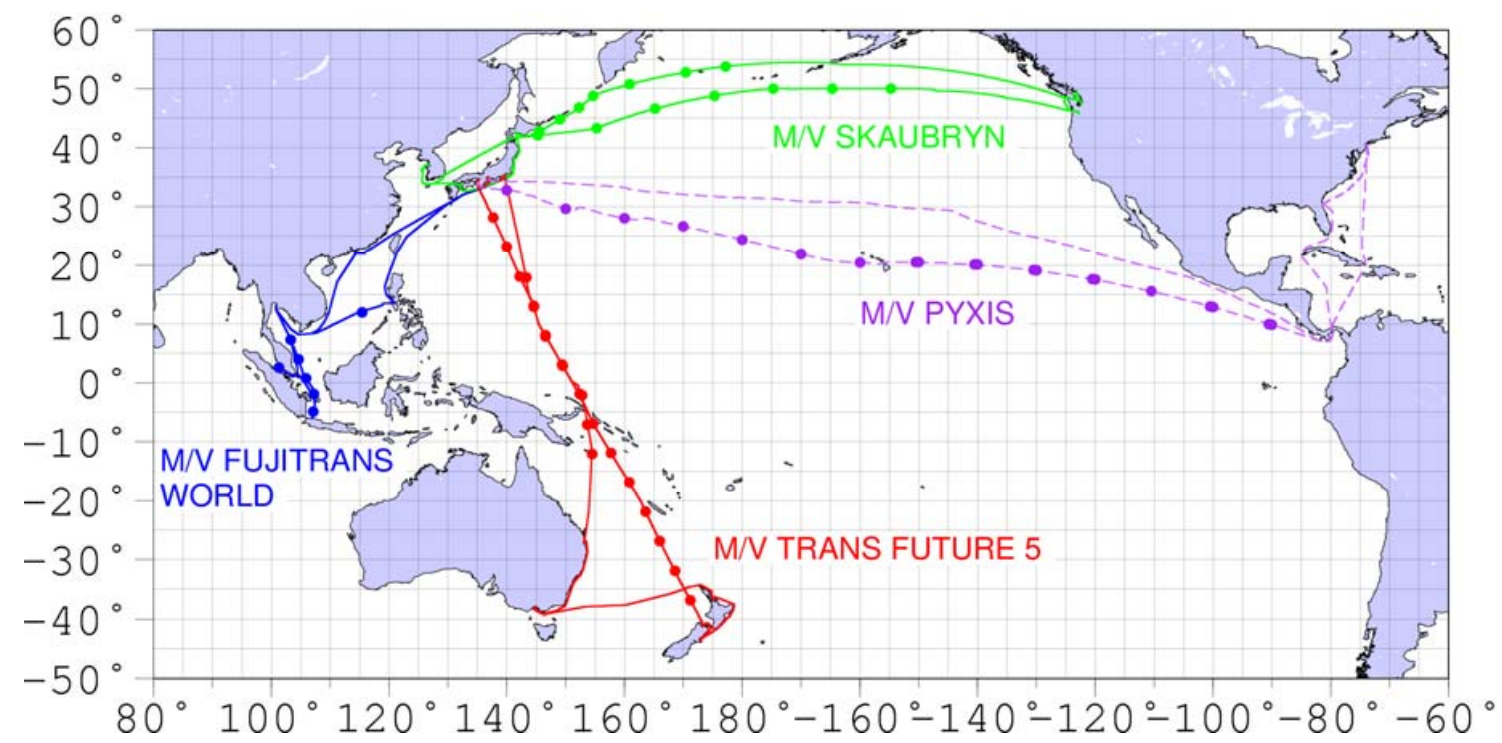

Fig. 1. Current geographical coverage of atmospheric monitoring in the NIES VOS program: Southeast Asia route by Fujitrans World (blue); North America route by Pyxis (purple) and Skaubryn (green); Oceania route by Trans Future 5 (red). For atmospheric CO, both continuous measurement and flask sampling followed by GC/RGD analysis are being conducted along the three routes indicated by solid lines, whereas only flask sampling is conducted along the route indicated by the dashed lines. Dots denote flask sampling points.

interval), between Japan and Canada (North America route, 8-week interval), and between Japan and Australia and New Zealand (Oceania route, 6-week interval), respectively.

\subsection{Setup for atmospheric observations}

We set up a laboratory in a room in the cabin of each ship, and installed an observation system customized for atmospheric monitoring. The system needs to be robust because it runs in automatic mode under the relatively severe conditions on a ship during cruises (e.g. conditions created by vibration from the ship's engine and sea swell). Moreover, for the ship's safety, the instruments do not allow the use of hazardous substances and gases. Our observation system consists of an atmospheric observation system and a data management system. Electric power is supplied by the ship's generator through a transformer equipped with an automatic voltage regulator and an uninterruptible power supply to provide rectified electric current, because the voltage of the ship-generated electric power fluctuates. A constant voltage and constant frequency unit is used for the continuous measurement system.

\subsection{Atmospheric observation system}

The atmospheric observation system had consisted of a continuous measurement system of $\mathrm{CO}_{2}$ and $\mathrm{O}_{3}$, and a flask sampling system of long-lived trace gases for later laboratory analysis. Here a continuous measurement system of $\mathrm{CO}$ was newly installed on the ships in operation along three of the four routes: the Oceania route by M/V TF5, the North
America route by M/V SKB, and the Southeast Asia route by M/V FTW (Fig. 1). Prior to this installation, the CO mixing ratios were analyzed in flask samples only. Intakes to sample ambient air for continuous measurements and flask samplings are individually placed at the top deck of each ship to avoid or, at least, minimize contamination originating from the ship's exhaust.

For continuous measurements, ambient air sampled at the intakes are delivered to the observation room through stainless steel tubing for $\mathrm{CO}$ and $\mathrm{CO}_{2}$ while through Teflon tubing for $\mathrm{O}_{3}$ to avoid potential loss of $\mathrm{O}_{3}$ onto the metal surface. To remove dust and condensed water, air samples pass through a Teflon filter and a glass water trap before being introduced to the individual measurement systems. The detailed configurations of the $\mathrm{CO}_{2}$ and $\mathrm{O}_{3}$ measurement systems were reported in our previous publications (Watanabe et al., 2005; Chierici et al., 2006; Nara et al., 2011), and the CO measurement system will be described in the following section.

Flask air samples are collected with an automatic air sampler unit (SU701, Kimoto Electric Co., Osaka, Japan) for later laboratory analysis (Fig. 2). The sampling system consists of air sampling equipments, a cryogenic dryer, a metal bellows pump, a solenoid valve unit, an air compressor, and a controlling device. The air sampling equipment consists of seven sampling flasks (2.5-L Pyrex or 3.3-L electro-polished stainless steel flasks) equipped with two air-actuated stopcocks and sealed with Viton O-rings (for glass flasks) or NiCo alloy diaphragms (for stainless steel flasks). These flasks are housed in an aluminum case to prevent physical damage and to avoid sunlight, which might photodegrade gas species 


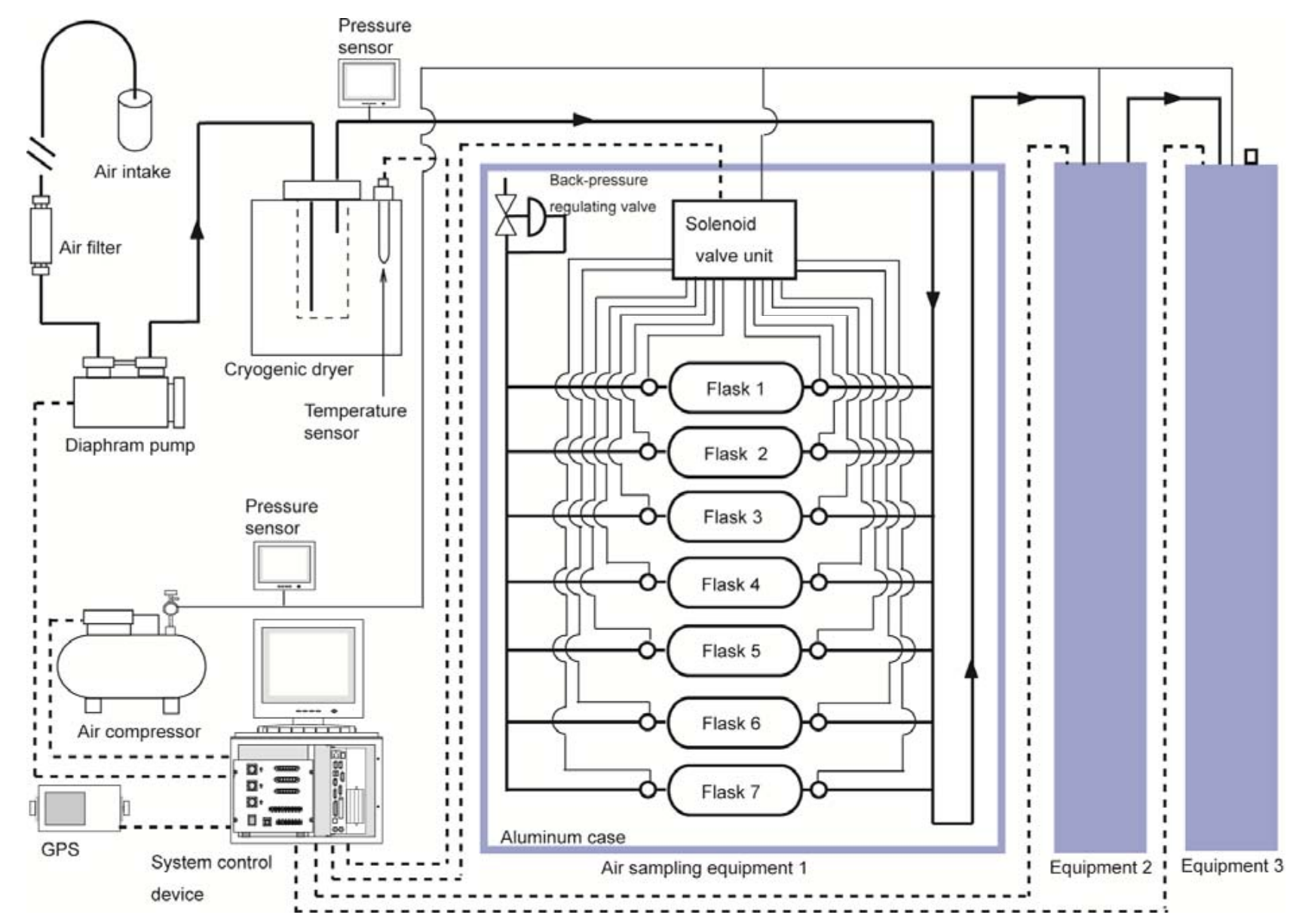

Fig. 2. Schematic diagram of a flask sampling system for the NIES VOS program. Thick and thin solid lines denote lines for sample and compressed air respectively. Thick dashed lines denote the electric wiring that connects the system control device with discrete components of the system.

(e.g. Novelli et al., 1992). The metal bellows pump (MB151, Metal Bellows Corp., MA, USA) and the solenoid valve unit are computer-controlled by means of the system control device. The solenoid valve unit controls the supply of compressed air to operate the air-actuated stopcocks. The system control device is linked to a GPS system, to which the latitude and longitude of the sampling locations (Fig. 1) are predesignated. Ambient air sampled at the air intake is drawn by means of the metal bellows pump through stainless steel tubing at a flow rate of 5 STP (standard temperature and pressure) $1 \mathrm{~min}^{-1}$. After the sampled air is dehumidified by passage through a cryogenic dehumidifier kept at about $-48^{\circ} \mathrm{C}$, the air is introduced into a glass or stainless steel sampling flask. The flask is rinsed by the sample air for the first $15 \mathrm{~min}$ (glass) or $5 \mathrm{~min}$ (stainless steel), followed by ambient air collection for 4-5 min, pressurized up to $1.57 \mathrm{MPa}$ and $2.45 \mathrm{MPa}$ for glass and stainless steel flasks, respectively. The line pressure and the operating records are logged to confirm completion of each sampling and to check the operating conditions after the voyage during maintenance access.
When the ship is berthed at its Japanese port, the air sampling equipment is removed from the ship and taken to NIES for analysis. All the flask samples are typically analyzed within 1 to 2 month after collection of ambient air. Mixing ratios of $\mathrm{CO}$ as well as $\mathrm{CO}_{2}, \mathrm{CH}_{4}, \mathrm{~N}_{2} \mathrm{O}, \mathrm{H}_{2}$, and $\mathrm{SF}_{6}$ in the glass flasks are determined by means of the procedure of Machida et al. (2008). For CO quantification, a GC/RGD instrument (RGD-2, Trace Analytical, Menlo Park, CA, USA; or Peak Performer, Peak Laboratories, Mountain View, CA, USA) is used (typical analytical precision $0.3 \mathrm{ppbv}$ ). The mixing ratios of hydrochlorofluorocarbons, perfluorocarbons, methyl chloride, methyl bromide, methyl iodide, tetrachloroethylene, trichloroethylene, chloroform, dimethyl sulfide, isoprene, $n$-pentane, and benzene in the stainless steel flasks are determined by GC coupled with mass spectrometry (Li et al., 1999). 


\subsection{Data management system}

The data management system consists of a data server and a display client. All the instruments in the atmospheric observation room are linked with one another via a local area network, providing measurement data every 10 seconds. The data server reads these 10 -s data from the individual instruments and integrates the data after synchronizing them to UTC obtained from the GPS. These integrated files are then stored on the data server as 10-s- and 1-min-averaged data for further data processing. The display client simultaneously displays ship tracks and temporal variations for selected species on a 24-h scale. The display client is set to print the displayed data once a day as a daily report. The ship's crew inspects the atmospheric observation system daily to make sure that it is operational. The printed daily report and a completed checklist are sent from the ship to NIES by e-mail. If any abnormal condition is found in the daily report or the checklist, we contact the ship crew to shut down the instrument for the ship's safety, if necessary.

\section{Continuous CO measurement system}

We use a commercially available GFC/nondispersive infrared CO analyzer (Model 48C or 48i, Thermo Electron Inc., Franklin, MA, USA) equipped with a sample dryer unit (SDU) and a calibration control unit (CCU) customized for use onboard the ships. The GFC detector operates on the principle that $\mathrm{CO}$ absorbs infrared radiation at a wavelength of $4.6 \mu \mathrm{m}$. Some other trace gases also absorb at this wavelength, such as water vapor $\left(\mathrm{H}_{2} \mathrm{O}\right)$ and $\mathrm{CO}_{2}$, and these gases can interfere with CO quantification at ppbv levels (Dickerson and Delaney, 1987; Fried et al., 1991). Although $\mathrm{CO}_{2}$ absorbs in the infrared too, $\mathrm{H}_{2} \mathrm{O}$ has a greater effect on $\mathrm{CO}$ quantification because there is a large amount of $\mathrm{H}_{2} \mathrm{O}$ in the atmosphere. Dickerson and Delany (1987) reported that interference by $\mathrm{H}_{2} \mathrm{O}$ can be reduced by drying the air samples. Nedelec et al. (2003) estimated the $\mathrm{H}_{2} \mathrm{O}$ interference to be about 6 ppbv $\mathrm{CO}$ per $\mathrm{hPa} \mathrm{H}_{2} \mathrm{O}$ for their GFC system. Because we used dry $\mathrm{CO}$-in-air gas standards to calibrate the GFC sensitivity, $\mathrm{H}_{2} \mathrm{O}$ removal from the sample air was required in order to eliminate $\mathrm{H}_{2} \mathrm{O}$ interference expected for humid air samples collected from marine air masses over the ocean.

In addition to $\mathrm{H}_{2} \mathrm{O}$ interference, drift of background signals generates uncertainty in the $\mathrm{CO}$ determination. Because substantial background drift occurs in response to changes in ambient temperature over short periods (from minutes to an hour), the changes in the signal intensity have to be corrected for if $\mathrm{CO}$ is to be precisely quantified. To overcome these analytical difficulties on the ships, we use a sample dryer unit and an automatic calibration unit for the continuous CO measurements. Here we describe in detail the design and performance of the continuous $\mathrm{CO}$ measurement system, including the quantification method and quality assurance and quality control measures.

\subsection{Sample dryer unit}

The CO measurement system is shown schematically in Fig. 3. The SDU $(500 \mathrm{~mm}$ depth $\times 300 \mathrm{~mm}$ wide $\times 500 \mathrm{~mm}$ high; mass $20 \mathrm{~kg}$ ) consists of an oil-less diaphragm pump, an electric cooler, a peristaltic tubing pump, and a Nafion Perma Pure dryer. Teflon tubing ( $1 / 4$ inch) is used for all the plumbing to prevent $\mathrm{CO}$ losses to the inner surface of the tubing. The diaphragm pump (MOA-P108, GAST Manufacturing Inc., Benton Harbor, MI, USA) draws ambient air from the air intake and subsequently feeds the air to the electric cooler (thermoelectric dehumidifier, DH-109, Komatsu Electronics Inc., Kanagawa, Japan) at a flow rate of $4.51 \mathrm{~min}^{-1}$ to dehumidify the air to a dew point of $1-3^{\circ} \mathrm{C}$. The condensed water in the cooler is drained by the peristaltic tubing pump ( $\mathrm{PB}$ series 7017, Masterflex, Barrington, IL, USA) at a flow rate of $4.8 \mathrm{ml} \mathrm{min}^{-1}$. The dried air stream is further dehumidified by passage through the Nafion Perma Pure dryer (PD-50T24MKR, Japan Controls Co., Tokyo, Japan) with the help of the pressure difference between the sample and purge gases. A countercurrent as a purge gas for the dryer is generated by partial diversion of the main sample flow: the sample stream $\left(4.51 \mathrm{~min}^{-1}\right)$ is split into a $1.51 \mathrm{~min}^{-1}$ main sample flow and a $3.01 \mathrm{~min}^{-1}$ purge gas flow by means of a pressure regulating valve to optimize the drying capacity. The two-step drying procedure provides a $1.51 \mathrm{~min}^{-1}$ dry airstream at a dew point below $-30^{\circ} \mathrm{C}$.

\subsection{Calibration control unit}

The CCU is $430 \mathrm{~mm}$ depth $\times 482.6 \mathrm{~mm}$ wide $\times 132.5 \mathrm{~mm}$ high and has a mass of $15 \mathrm{~kg}$ (Fig. 3). Its main components are solenoid valves, pressure regulating valves, two mass flow controllers, and a $\mathrm{CO}$ scrubber. The sample gas, standard gas, and nitrogen gas are connected to the CCU, and the gas pressures are adjusted to approximately $0.05 \mathrm{MPa}$ by back-pressure and forward-pressure regulating valves. Operation of each three-way solenoid valve is controlled by an electric time relay switch (Daily Time Switch, H5L-A, Omron, Tokyo, Japan). The dry sample stream from the SDU is introduced to the CCU, and by switching the solenoid valves, the gas stream can be directed either to the GFC directly or to the GFC through the CO scrubber. The flow rates of these gas streams are kept at $800 \mathrm{~mL} \mathrm{~min}^{-1}$ by a mass flow controller (Thermal Mass Flow Controller 3660, Kofloc, Tokyo); the air stream is introduced to the GFC, and the excess $700 \mathrm{ml} \mathrm{min}^{-1}$ of sample stream is exhausted to the outside. Injection of nitrogen gas is controlled with a manually operated two-way solenoid valve. The nitrogen gas is used to purge the optical cell of the GFC to prevent absorption of particles and polar substances onto the cell surface, and the nitrogen gas is introduced into the GFC at a flow rate 


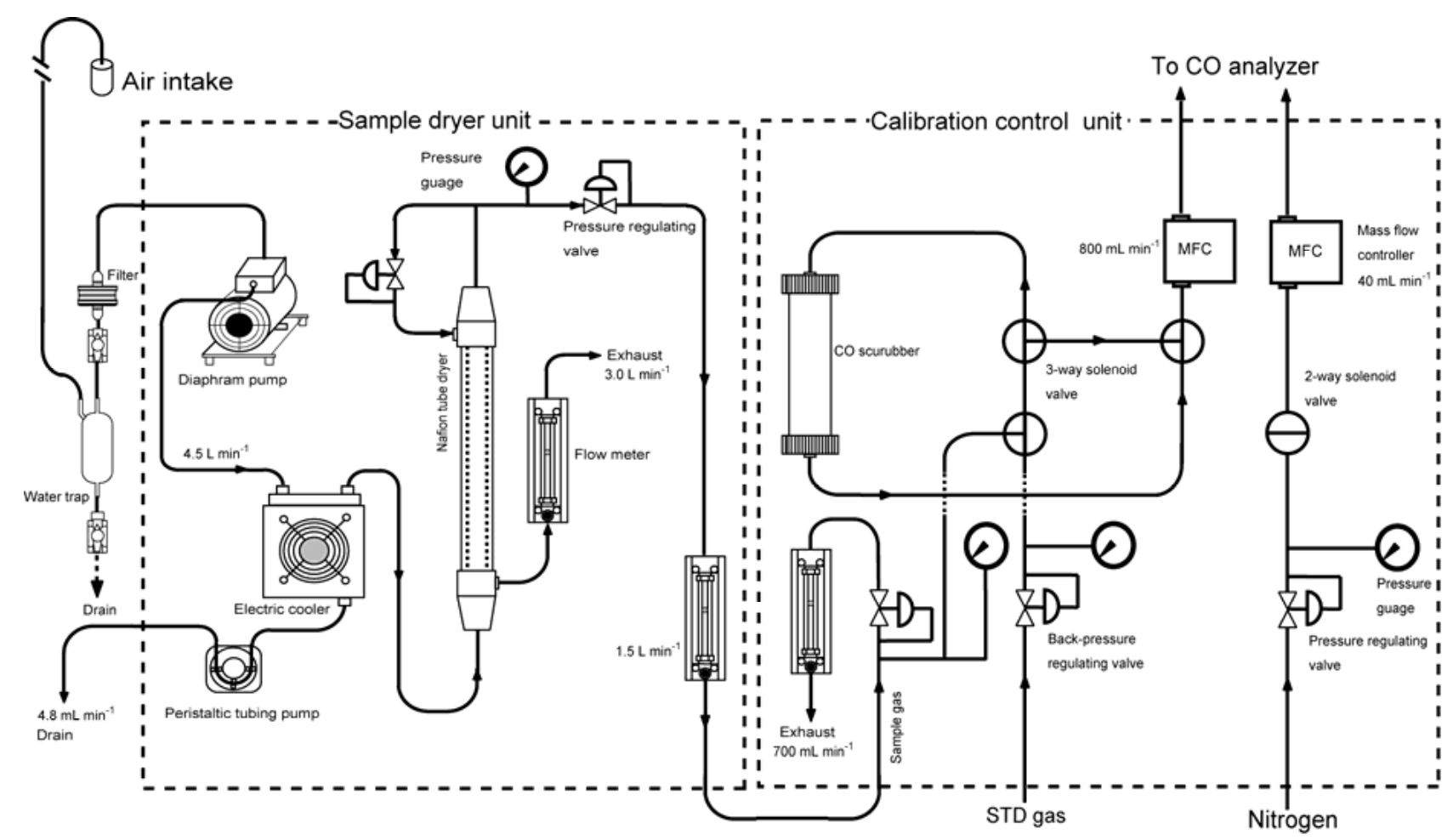

Fig. 3. Schematic diagram of the continuous $\mathrm{CO}$ measurement system, including a sample dryer and a calibration control unit.

of $40 \mathrm{ml} \mathrm{min}^{-1}$, which is adjusted by means of another mass flow controller.

$\mathrm{CO}$-free gas (zero-air) is produced inside the $\mathrm{CCU}$ by passage of the sample air stream through the $\mathrm{CO}$ scrubber. We used SOFNOCAT 514 (Molecular Products, Thaxted, Essex, UK), a hydrophobic $\mathrm{CO}$ oxidizing agent, to scrub $\mathrm{CO}$ from ambient air without altering the humidity. Nedelec et al. (2003) used SOFNOCAT to produce zero-air in their $\mathrm{CO}$ measurement system installed onboard MOZAIC aircraft and determined the $\mathrm{CO}$ removal rate during long-term operation. We calculated the rate of CO removal by SOFNOCAT in the experiments carried out onboard the ships by comparing the GFC signal intensities of zero-air generated through SOFNOCAT with those of synthetic air, which is free of CO (Japan Fine Products, Kanagawa, Japan). No substantial deterioration in $\mathrm{CO}$ removal capacity was found beyond the analytical precision of the GFC while ambient air temperature and humidity varied between 7.6 and $30.1^{\circ} \mathrm{C}$ and between 48.5 and $84 \%$, respectively. In addition, our periodic checks during maintenance of the observation instruments demonstrated that the CO removal capacity of SOFNOCAT remained constant for at least 1 year of continuous usage on the ship.

\subsection{GFC detection unit}

Before the GFC was installed on the ships, its analytical performance was evaluated. The analytical precision and

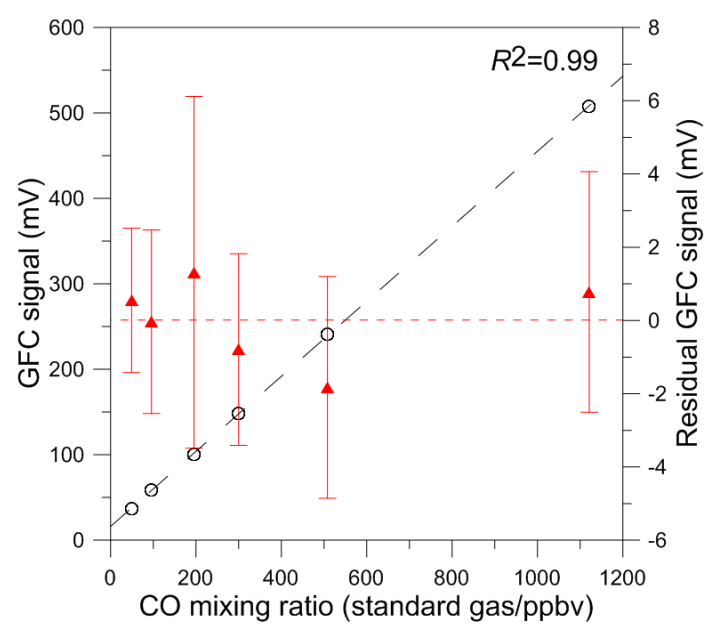

Fig. 4. Linear response of GFC signals versus $\mathrm{CO}$ mixing ratios in the NIES 09 CO scale (open circles) determined by VURF. Averages of the GFC signal residual from the fitting line at each $\mathrm{CO}$ mixing ratio are also plotted (triangles) with $1 \sigma$ values as vertical bars. The residual GFC signal of $1 \mathrm{mV}$ corresponds to approximately 2 ppbv.

detection limit of the GFC were evaluated with six highpressure cylinders containing $\mathrm{CO}$ balanced with purified air at known mixing ratios $(49.25,95.98,195.48,300.01$, 508.25 , and $1121.50 \mathrm{ppbv}$ ), which were calibrated against 
the NIES 09 CO scale. From replicate measurement of these gases for $10 \mathrm{~min}$, the analytical precision was determined to be $10 \mathrm{ppbv}( \pm 1 \sigma)$ for different $\mathrm{CO}$ levels, indicating no dependency on the $\mathrm{CO}$ mixing ratio within the range examined here. The detection limit was determined by analysis of CO-free air for $20 \mathrm{~min}$. The variability of the baseline CO signals for $20 \mathrm{~min}$ corresponded to $6 \mathrm{ppbv}( \pm 1 \sigma)$, and the resulting detection limit was determined to be $18 \mathrm{ppbv}$ ( $3 \sigma$ of the measurement). The linearity of the GFC response was tested with a vacuum ultraviolet resonance fluorescence CO analyzer (VURF, Ultra-fast carbon monoxide analyzer, Aero-Laser GmbH, Garmisch-Partenkirchen, Germany), which has an excellent linear response to $\mathrm{CO}$ mixing ratios over a wide range (Gerbig et al., 1996, 1999). The GFC signal intensity is plotted against the $\mathrm{CO}$ mixing ratios determined by the VURF instrument in Fig. 4. Least-squares fitting gave a determination coefficient $\left(R^{2}\right)$ of 0.99 for $\mathrm{CO}$ mixing ratios ranging from 49 to $1122 \mathrm{ppbv}$. The residual of the GFC signals from the fitting line at each mixing ratio was well distributed within the typical analytical precision, demonstrating the good linearity of the GFC response.

\subsection{CO quantification}

In our $\mathrm{CO}$ measurement system, sample air and zero-air are introduced into the GFC alternately on a 1-h cycle: sample air for $40 \mathrm{~min}$ followed by zero-air for $20 \mathrm{~min}$ to correct for background drift during ambient air measurement. For correction of the day-to-day variability in the GFC sensitivity, standard gas is injected to the GFC for 10 min once a day. The CO mixing ratios are calculated from the mean signal intensity of the sample gas for $40 \mathrm{~min}$ with reference to the mean signal intensity of the standard gas after correction for the background drift of the GFC. The background drift during sample and standard gas injection is estimated by linear interpolation between two averaged signal intensities for zero-air, which is injected before and after measurements of sample or standard gas. The net signal intensities are calculated by subtracting the interpolated background signals from the average signal intensity of sample and standard gas. To eliminate possible contamination from the ship's exhaust, we evaluated $\mathrm{CO}$ data against empirical criteria established from $\mathrm{CO}_{2}$ measurements. When $\mathrm{CO}_{2}$ data are processed, 10-min averages and standard deviations are calculated from 10-s data. When the mean $\mathrm{CO}_{2}$ values exceed $3 \sigma$, corresponding $\mathrm{CO}$ data are judged as indicating contamination. Along the Southeast Asia route, the $\mathrm{CO}$ data are evaluated on the basis of $\mathrm{CO}_{2}$ and $\mathrm{O}_{3}$ data because local emission sources, including biomass burning, are common, resulting in high temporal variability.

We used a $\mathrm{CO}$ standard gas balanced with purified air at a mixing ratio of approximately $1.1 \mathrm{ppmv}$ as a reference gas for CO quantification by GFC (Fig. 5). Novelli et al. (2003) reported that gas standards drift to higher $\mathrm{CO}$ values in highpressure cylinders over time. Tanimoto et al. (2007) re- ported the possibility of artificial $\mathrm{CO}$ production on the metal surface inside the cylinders of air-balanced $\mathrm{CO}$ standards, whereas this effect is negligible for $\mathrm{N}_{2}$-balanced $\mathrm{CO}$ standards. For this reason, the use of a $\mathrm{N}_{2}$-balanced $\mathrm{CO}$ standard gas is preferable, but GFC measurements require airbalanced CO standard gases owing to the changes in GFC sensitivity in the presence of $\mathrm{O}_{2}$. To overcome these problems, we use $\mathrm{CO}$ standard gases balanced with air at the ppmv level to minimize CO increases, because the rate of $\mathrm{CO}$ increase is typically on the order of several ppbv per year (Novelli et al., 1994). In our study, we referenced all the CO mixing ratios to the NIES 09 CO scale. In 1996 NIES established a scale for $\mathrm{CO}$ measurements by preparing four CO-in-air gravimetric gas standards in 9.4-1 highpressure aluminum cylinders (NIES 96 scale; CO mole fractions: ca. 50, 150, 250, and $350 \mathrm{ppbv}$ ). The NIES 96 scale was in use from 1996 to 2008. In 2008, the NIES $\mathrm{CO}$ scale was changed to reference ppmv-level gas standards (NIES 09 scale) to minimize the effects of the artificial CO increases described above. The NIES $09 \mathrm{CO}$ scale consists of four air-balanced CO standard gases in 9.41 high-pressure aluminum cylinders prepared gravimetrically at 2030, 3028, 4027, and $5032 \mathrm{ppbv}$. These gas standards are quantified by a VURF instrument. The background signals are determined with CO-free air (zero-air) produced by passing purified air ( $<5$ ppbv CO) through SOFNOCAT 514. The NIES CO scales are periodically examined by means of rigorous calibration with gravimetrically prepared standard gases and through international comparisons with scales from other laboratories. For example, the NIES $09 \mathrm{CO}$ scale was compared to the WMO-2004 scale maintained by the NOAA/Earth System Research Laboratory's Global Monitoring Division in a round-robin intercomparison project in 2002-2007, and the scale was assessed in the Cucumber CarboEurope intercomparison experiment in 2008. These intercomparisons indicated that the NIES $09 \mathrm{CO}$ scale is higher than the WMO-2004 scale by $10-11 \mathrm{ppbv}$ at the $150 \mathrm{ppbv}$ level and by $12-13 \mathrm{ppbv}$ at the $310-330 \mathrm{ppbv}$ level (Katsumata et al., 2011).

We determine the $\mathrm{CO}$ increase in the standard gases used to quantify the $\mathrm{CO}$ mixing ratios by means of continuous measurements and flask analysis. The evolution of $\mathrm{CO}$ relative to the original $\mathrm{CO}$ mole fraction in our $\mathrm{CO}$ standard gases is shown in Fig. 5. Although the $\mathrm{CO}$ mole fraction in all standard gases increases over time, the impact of the $\mathrm{CO}$ increase for continuous measurements (ppmv-level) is clearly minimal. In contrast, the standard gases prepared at ppbv-level show substantial $\mathrm{CO}$ increases. The rates of $\mathrm{CO}$ increase in these standard gases are high, ranging from 8 to $19 \mathrm{ppbv} \mathrm{yr}^{-1}$, whereas those reported by NOAA are only $1-$ $2 \mathrm{ppbv} \mathrm{yr}^{-1}$ (Novelli et al., 1994). These results suggest that high-frequency calibration of $\mathrm{CO}$-in-air standard gases at the ppbv-level will be required in order to sustain primary calibration scales of $\mathrm{CO}$ in individual laboratories. 

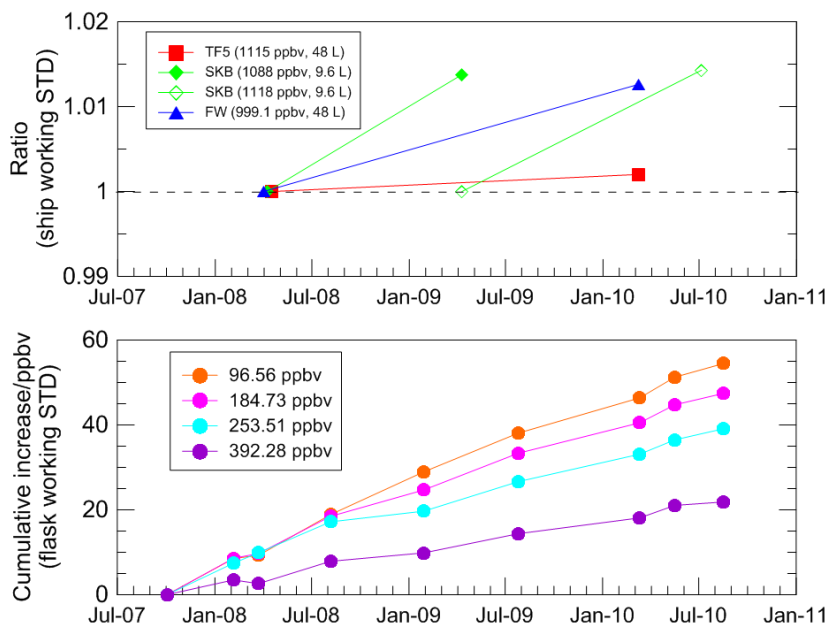

Fig. 5. Calibration history of CO gas standards used for continuous onboard CO measurement (upper panel) and flask analysis (lower panel). Note that onboard $\mathrm{CO}$ standard gases were calibrated before and after use, whereas the standards for flask analysis were calibrated periodically.

\section{Quality assurance and quality control of $\mathrm{CO}$ monitoring}

\subsection{Comparison of continuous and flask measurements}

Ambient $\mathrm{CO}$ mixing ratios observed continuously on the ships in various regions over the Pacific Ocean are shown in Fig. 6, along with ratios determined by GC/RGD analysis of flask samples. In general, continuous measurements and flask analysis data agreed reasonably well. The continuous measurements along the Oceania and the North America routes revealed smooth and homogeneous variations of $\mathrm{CO}$, which are typical for the clean atmosphere in remote regions; in contrast, short-term variations were captured near ports in the Northern Hemisphere. Along the Southeast Asia route, the continuous measurements clearly captured the high variability of $\mathrm{CO}$ due to regional pollution, and the flask analyses missed many elevated peaks. These results suggest that the continuous measurements by GFC are more useful than flask analyses particularly along the Southeast Asia route, despite the fact that the analytical precision of GFC is poorer than that of GC/RGD.

\subsection{Consistency of continuous and flask analyses}

The CO mixing ratios obtained by continuous measurement and by flask analyses were scrutinized to evaluate the consistency and robustness of both the measurement techniques and the gas standards. The flask samples were collected and analyzed between November 2005 and June 2010 for the Oceania route, between July 2007 and March 2010 for the North America route, and between September 2007 and May 2010 for the Southeast Asia route. After screening for contamination from the ships, the numbers of flask samples used for the comparison were 723, 96, and 115 in total for the Oceania, North America, and Southeast Asia route, respectively.

Scatter plots of continuous measurement data versus flask analysis data for the three shipping routes are shown in Fig. 7. We see good agreement between these two different methods for all the three routes. Although a few outliers were observed in each dataset, they likely originated from a mismatch between the averaging time for the continuous measurements (40 min) and the discrete and instantaneous sampling time for the flasks. The excellent linear relationships between the two $\mathrm{CO}$ datasets did not depend significantly on the mixing ratios, demonstrating that there was neither significant degradation nor growth of $\mathrm{CO}$ in the flask samples during storage after collection.

The temporal variations and relative frequency distributions of the differences between the two datasets are shown in Fig. 8. The differences showed Gaussian distributions, and $87 \%, 93 \%$, and $80 \%$ of the data from the Oceania, North America, and Southeast Asia routes, respectively, fell within the range of typical GFC analytical precision $( \pm 10 \mathrm{ppbv})$. The average values were close to zero ( -1.8 to $2.7 \mathrm{ppbv})$, and the standard deviations were less than $10 \mathrm{ppbv}$ (5.3$7.5 \mathrm{ppbv})$. The long-term trends of the differences during the past 3-5 years were neither systematic nor substantial for any of the Oceania, North America, and Southeast Asia data, beyond the GFC analytical precision of \pm 10 ppbv. For the Oceania data, differences seemed to increase slightly during the latter half of 2008, remain constant until early 2010, and then drop back to close to zero. Such temporal variations may reflect minor issues in either the continuous measurements or the flask analysis data, warranting further study. Nevertheless, the differences over the last 5 years were well within the typical GFC analytical precision. These results demonstrate the internal consistency between the two different techniques with different gas standards.

\section{Preliminary results of continuous CO measurements}

The CO distributions in different seasons from March 2008 to February 2009 are presented in Fig. 9 for the combined data for all three VOS observations. Along the Oceania route, enhancements of $\mathrm{CO}$ were observed in the northern midlatitude region, particularly during the boreal winter (Figs. 6 and 9d), due likely to continental outflow from East Asia driven by a Siberian high-pressure system. Except in the mid-latitude region in the Northern Hemisphere, CO mixing ratios were generally lower than those observed along the other routes, and the ratios showed a smooth southward decreasing gradient. We attribute this north-to-south gradient mainly to the localization of the CO sources in the Northern Hemisphere. The north-to-south gradient was larger in the boreal winter than in the boreal summer (Fig. 9b), reflecting 

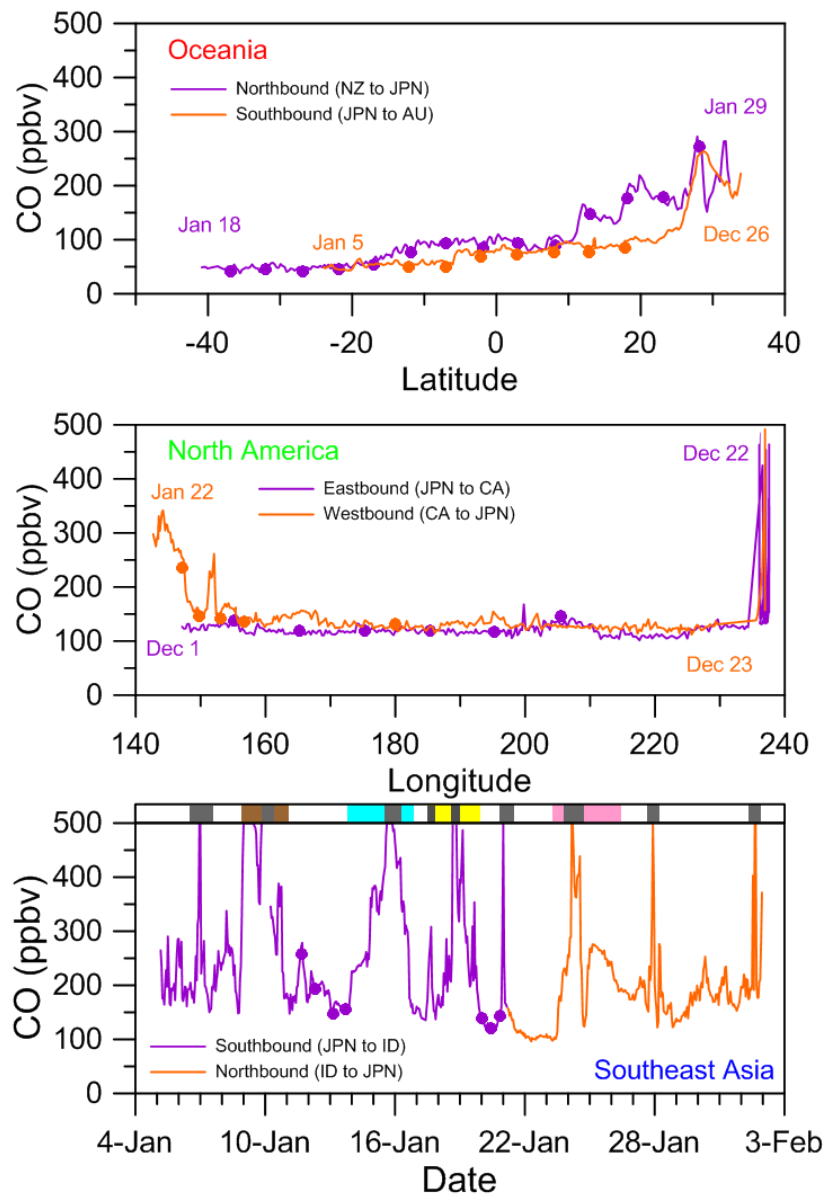

Fig. 6. Variations of $\mathrm{CO}$ mixing ratio observed by the three ships from December 2008 to January 2009 as a function of latitude (Oceania route), longitude (North America route), and date (Southeast Asia route): continuous data (lines) and flask analysis data (solid circles). Four distinct $\mathrm{CO}$ increase episodes are indicated by color coding across the top of the bottom panel: episode 1, brown; episode 2, cyan; episode 3, yellow; episode 4, pink. Gray denotes the ship's berthing at each port. For more details, see Sect. 5.

typical CO seasonality (maximum in winter and minimum in summer) in each hemisphere. The observed $\mathrm{CO}$ distributions along the Oceania route were consistent with previous observations at remote sites (e.g. Novelli et al., 2003), suggesting that the Oceania route captured typical background $\mathrm{CO}$ mixing ratios in both hemispheres over the Pacific Ocean.

Along the North America route, the $\mathrm{CO}$ mixing ratios showed a longitudinally homogeneous distribution in the northern North Pacific between 160 and $230^{\circ}$ E. A seasonal maximum and minimum were observed in the boreal spring (Fig. 9a) and boreal summer (Fig. 9b), respectively. A small longitudinal gradient, decreasing from west to east, was observed in the $\mathrm{CO}$ distribution during all four seasons (see Fig. 6 as an example of the longitudinal gradient in the boreal winter). The maximum longitudinal gradient was observed
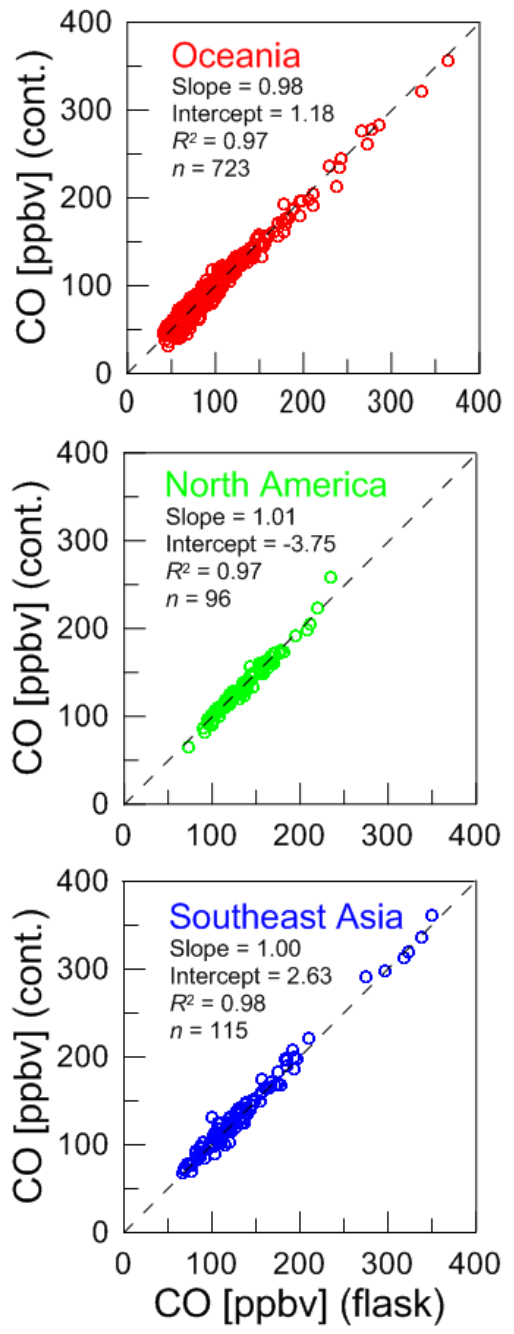

Fig. 7. Scatter plots of $\mathrm{CO}$ mixing ratios obtained by continuous (cont.) measurements against ratios obtained by flask analyses (flask) for the Oceania, North America, and Southeast Asia route. The dashed lines indicate the 1:1 correspondence lines.

in the boreal spring, which coincided with the maximum mixing ratios. This result suggests that the $\mathrm{CO}$ mixing ratios along the North America route were perturbed by Eurasian continental emission sources in the boreal spring. Tanimoto et al. (2008b) reported springtime CO enhancement at Rishiri Island in northern Japan due to biomass burning in eastern Siberia. Biomass burning may contribute to the $\mathrm{CO}$ maximum in the boreal spring.

In contrast to the $\mathrm{CO}$ distributions along the Oceania and North America routes, the $\mathrm{CO}$ distribution along the Southeast Asia route showed large temporal and spatial variations. The overall CO mixing ratios along this route were markedly higher than along the other two routes, showing a maximum in December-February (Fig. 9d) and a minimum in JuneAugust (Fig. 9b). Systematic atmospheric observation has not been performed in Southeast Asia, and our observation 


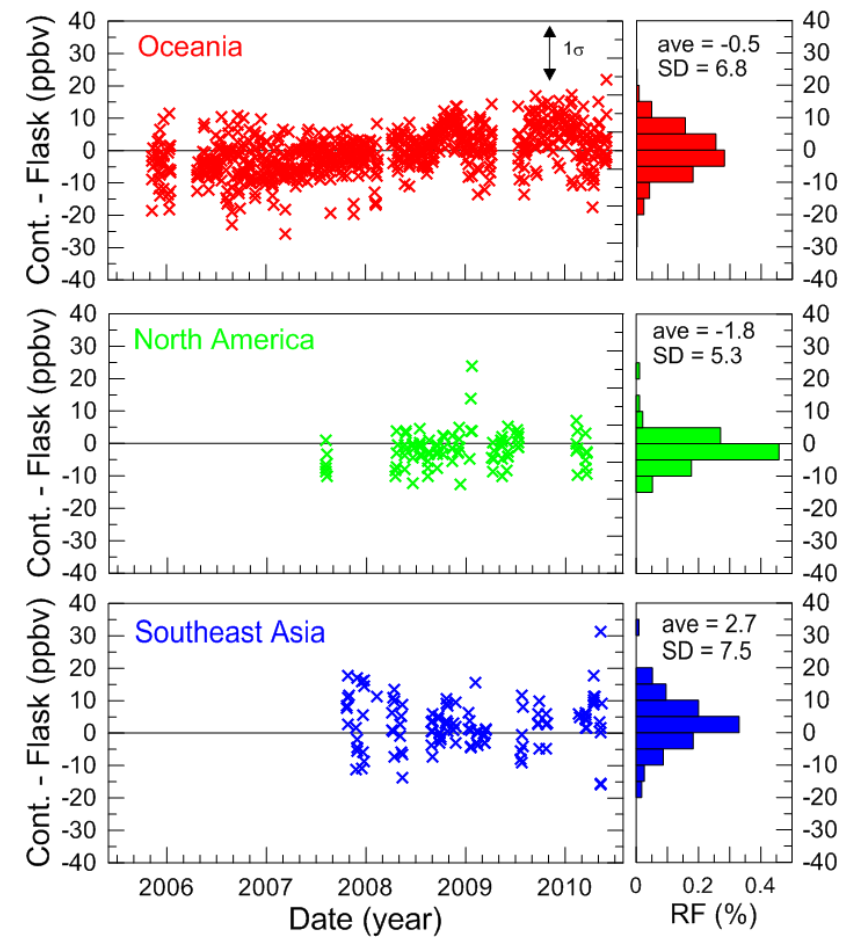

Fig. 8. Temporal variations (left panel) and relative frequency (RF) distributions (right panel) of the differences between continuous (cont.) measurements and flask analysis measurements for the Oceania, North America, and Southeast Asia route. The typical analytical precision of continuous measurements by GFC $(1 \sigma)$ is illustrated by a doubled-headed arrow (left panel). The averages and standard deviations (SD) are also indicated (right panel). Each bin is 5 ppbv.

reveals several important features of the $\mathrm{CO}$ distribution, especially during the northern winter. We describe four distinct episodes (Figs. 6 and 9d). In episode 1, a prominent $\mathrm{CO}$ enhancement was observed when the ship sailed in the coastal region of China. During the northern winter, atmospheric circulation in the Asian region is driven by continental outflow: air masses that pass over the East Asian continent travel to the East/South China Sea, whereas the East Asian region is covered during the northern summer season by clean maritime air from the Pacific. The $\mathrm{CO}$ enhancement was most likely due to the prevailing continental outflow, which efficiently picked up anthropogenic emissions from the surface and transported CO from East Asian continent to the East/South China Sea. In episode 2 and 4, the CO mixing ratios increased when the ship sailed in the coastal area of Indochina. Several previous studies reported that biomass burning activity becomes high during the dry season in Indochina (December-April; Pochanart et al., 2003; Kondo et al., 2004). Our backward trajectory analysis indicated that the ship captured air masses that passed over Indochina within a day, suggesting that biomass burning affected the $\mathrm{CO}$ distribution. In episode 3 , the $\mathrm{CO}$ mixing ratios increased when the ship sailed in the Strait of Malacca. A variety of ships constantly sail in the strait, and therefore $\mathrm{CO}$ emissions from ships have a large impact in this region. As is not clear in Fig. 9c, $\mathrm{CO}$ enhancement is often observed during the late dry season in Indonesia (September-November) around the southern part of the South China Sea, owing to the extensive biomass burning associated with agricultural activity in Borneo (Nara et al., 2011). Thus, the Southeast Asia route captured several important polluted outflows containing high CO mixing ratios.

\section{Summary and conclusions}

Atmospheric $\mathrm{CO}$ mixing ratios were continuously measured over the Pacific Ocean on commercial cargo vessels participating in the NIES VOS program. For onboard CO measurements, an in situ CO measurement system was developed employing a commercially available GFC instrument combined with a customized sample dryer unit and a calibration control unit. The excellent linearity of the GFC data, verified by means of a VURF instrument, allowed the use of ppmv-level CO-in-air gas standards. Use of the gas standards onboard the ships minimized the influence of drift in background signals and the sensitivity of the GFC instruments. The standard gases were also calibrated against the NIES 09 CO scale before and after use to correct for artificial CO increases in the working gas standards used on the ships. Comparison between the NIES $09 \mathrm{CO}$ scale and the WMO-2004 scale indicated that the former was higher than the latter by $10-11 \mathrm{ppbv}$ at the $150-$ ppbv level and by $12-$ 13 ppbv at the 310-330-ppbv level.

The CO mixing ratio data obtained by continuous measurement were compared with data obtained by flask sampling and subsequent laboratory GC/RGD analysis. The continuous $\mathrm{CO}$ data provided a more detailed picture of the $\mathrm{CO}$ distribution than did the flask sampling data, although the latter captured the general features of the $\mathrm{CO}$ distribution. In Southeast Asia, the flask analyses provided only marginal information on $\mathrm{CO}$ distribution, owing to the large spatial and temporal variations of $\mathrm{CO}$. These results clearly suggest the need for continuous measurements with high time resolution. Statistical analysis showed good consistency between the two datasets obtained with the two measurement techniques, demonstrating that the continuous measurement data had no systematic errors and biases relative to the flask sampling data for any of the three ships.

The CO observations by the three VOS ships revealed characteristic features of the $\mathrm{CO}$ distributions in the three regions. Along the Oceania route observed by TF5, a latitudinal gradient from north to south was observed, reflecting the fact that the majority of $\mathrm{CO}$ emission sources are located in the Northern Hemisphere. Along the North Pacific route of SKB, longitudinal distributions were relatively uniform with a slight west-to-east gradient in all seasons, likely due 

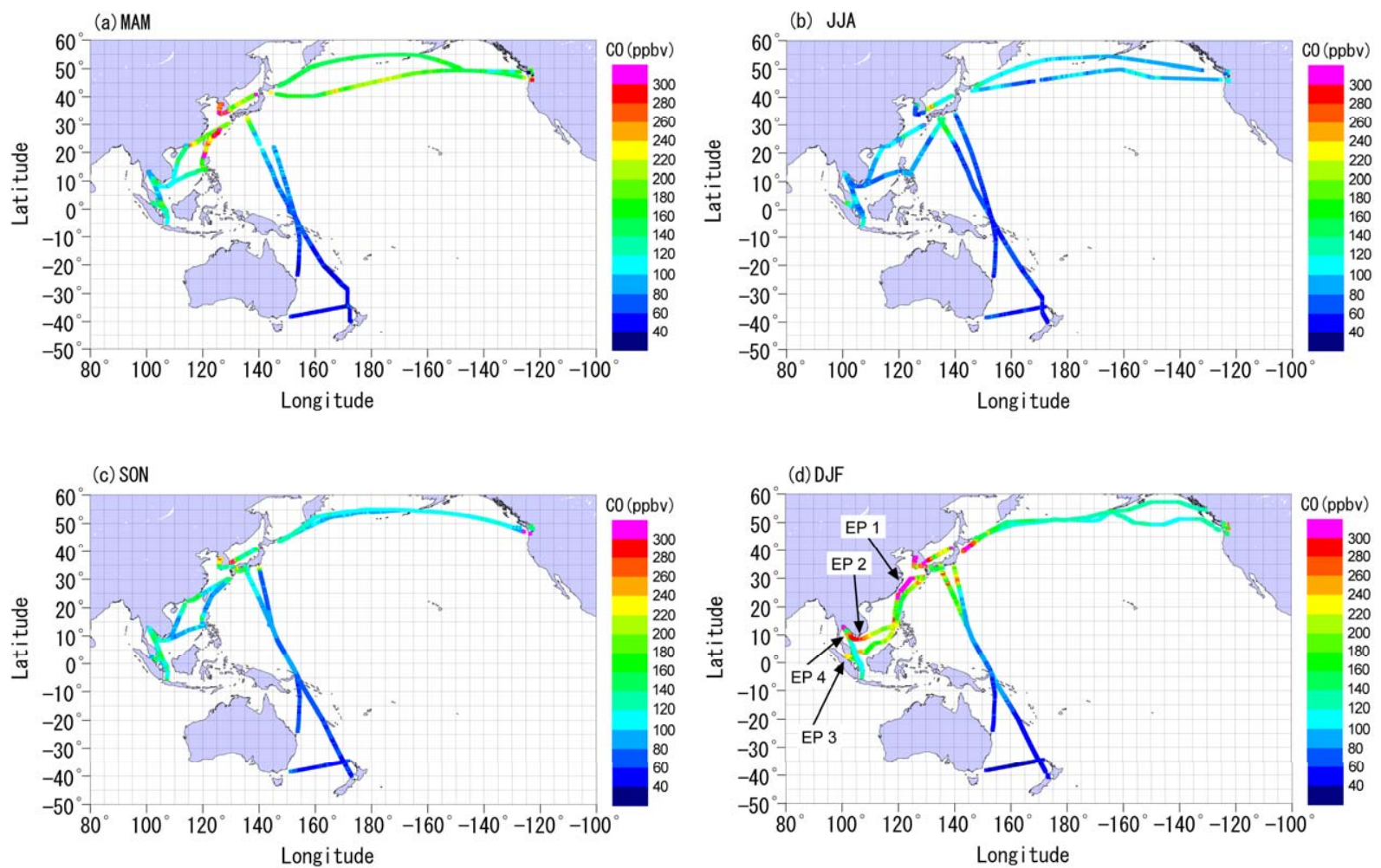

Fig. 9. Distribution of CO mixing ratios observed by three ships from March 2008 to February 2009: (a) March, April, and May (MAM), (b) June, July, and August (JJA), (c) September, October, and November (SON), (d) December, January, and February (DJF). Episode numbers (EP1, 2, 3, and 4) in (d) correspond to those in Fig. 6.

to substantial impacts from emission sources on the Eurasian continent. In contrast, data from the Southeast Asia route of FTW showed large spatial and temporal variations, due likely to the transport of polluted air masses of continental origin. Overall, these results suggest that the NIES VOS program is a useful platform for studying the global distribution of $\mathrm{CO}$, contributing to better understanding of the global $\mathrm{CO}$ budget.

Acknowledgements. We appreciate Toyofuji Shipping Co. for their generous cooperation with the NIES VOS program. We thank Y. Terao for valuable discussions and K. Katsumata for assistance in maintaining and calibrating the CO standard gas. We also thank S. Kariya, T. Yamada, and T. Nojiri of the Global Environmental Forum for their assistance with the observations. We are thankful to the anonymous reviewers for valuable comments and suggestions on this manuscript. This work was conducted with financial support of Global Environment Research Account for National Institutes provided by the Ministry of the Environment of Japan. Financial assistance was also provided by the Global Environment Research Fund (S-7) by the Ministry of the Environment of Japan.

Edited by: B. Buchmann

\section{References}

Brenninkmeijer, C. A. M., Crutzen, P. J., Fischer, H., Güsten, H., Hans, W., Heinrich, G., Heintzenberg, J., Hermann, M., Immelmann, T., Kersting, D., Maiss, M., Nolle, M., Pitscheider, A., Pohlkamp, H., Scharffe, D., Specht, K., and Wiedensohler, A.: CARIBIC - civil aircraft for global measurement of trace gases and aerosols in the tropopause region, J. Atmos. Ocean. Tech., 16, 1373-1383, 1999.

Brenninkmeijer, C. A. M., Crutzen, P., Boumard, F., Dauer, T., Dix, B., Ebinghaus, R., Filippi, D., Fischer, H., Franke, H., Frieß, U., Heintzenberg, J., Helleis, F., Hermann, M., Kock, H. H., Koeppel, C., Lelieveld, J., Leuenberger, M., Martinsson, B. G., Miemczyk, S., Moret, H. P., Nguyen, H. N., Nyfeler, P., Oram, D., O’Sullivan, D., Penkett, S., Platt, U., Pupek, M., Ramonet, M., Randa, B., Reichelt, M., Rhee, T. S., Rohwer, J., Rosenfeld, K., Scharffe, D., Schlager, H., Schumann, U., Slemr, F., Sprung, D., Stock, P., Thaler, R., Valentino, F., van Velthoven, P., Waibel, A., Wandel, A., Waschitschek, K., Wiedensohler, A., Xueref-Remy, I., Zahn, A., Zech, U., and Ziereis, H.: Civil Aircraft for the regular investigation of the atmosphere based on an instrumented container: The new CARIBIC system, Atmos. Chem. Phys., 7, 4953-4976, doi:10.5194/acp-7-4953-2007, 2007.

Brunke, E.-G., Scheel, H. E., and Seiler, W.: Trends of tropospheric carbon monoxide, nitrous oxide and methane as observed at Cape Point, South Africa, Atmos. Environ., 24A, 585-595, 1990.

Chierici, M., Fransson, A., and Nojiri, Y.: Biogeochemical pro- 
cesses as drivers of surface $f \mathrm{CO}_{2}$ in contrasting provinces in the subarctic North Pacific Ocean, Global Biogeochem. Cy., 20, GB1009, doi:10.1029/2004GB002356, 2006.

Dickerson, R. R. and Delaney, A. C.: Modification of a commercial gas filter correlation $\mathrm{CO}$ detector for enhanced sensitivity, J. Atmos. Ocean. Tech., 5, 424-431, 1987.

Fried, A., Henry, B., Parrish, D. D., Carpenter, J. R., and Buhr, M. P.: Intercomparison of tunable diode laser and gas filter correlation measurements of ambient carbon monoxide, Atmos. Environ, 25A, 2277-2284, 1991.

Gerbig, C., Kley, D., Voltz-Thomas, A., Kent, J., Dewey, K., and McKenna, D. S.: Fast response resonance fluorescence CO measurements aboard the C-130: Instrument characterization and measurements made during North Atlantic Regional Experiment 1993, J. Geophys. Res., 101, 29229-29238, 1996.

Gerbig, C., Smitgen, S., Kley, D., Volz-Thomas, A., Dewey, H., and McKenna, D. S.: An improved fast response vacuum UV resonance fluorescence CO instrument, J. Geophys. Res., 104, 1699-1704, 1999.

Katsumata, K., Machida, T., Tanimoto, H., Nara, H., and Mukai, H.: Re-evaluation of NIES CO scale using high concentration gravimetric $\mathrm{CO}$ standard gases, GAW research and monitoring reports, 194, 244-247, 2011.

Kondo, Y., Morino, Y., Takegawa, N., Koike, M., Kita, K., Miyazaki, Y., Sachse, G. W., Vay, S. A., Avery, M. A., Flocke, F., Weinheimer, A. J., Eisele, F. L., Zondlo, M. A., Weber, R. J., Singh, H. B., Chen, G., Crawford, J., Blake, D. R., Fuelberg, H. E., Clarke, A. D., Talbot, R. W., Sandholm, S. T., Browell, E. V., Streets, D. G., and Liley, B.: Impacts of biomass burning in Southeast Asia on ozone and reactive nitrogen over the western Pacific in spring, J. Geophys. Res., 109, D15S12, doi:10.1029/2003JD004203, 2004.

Li, H.-J., Yokoouchi, Y., and Akimoto, H.: Measurement of methyl halides in the marine atmosphere, Atmos. Environ., 33, 18811887, 1999.

Logan, J. A., Prather, M. J., Wofsy, S. C., and McElroy, M. B.: Tropospheric chemistry: A global perspective, J. Geophys. Res., 86, 7210-7254, 1981.

Machida, T., Matsueda, H., Sawa, Y., Nakagawa, Y., Hirotani, K., Kondo, N., Goto, K., Nakazawa, T., Ishikawa, K., and Ogawa, T.: Worldwide measurements of atmospheric $\mathrm{CO}_{2}$ and other trace gas species using commercial airlines, J. Atmos. Ocean. Tech., 25, 1744-1754, 2008.

Matsueda, H., Inoue, H. Y., Sawa, Y., Tsutsumi, Y., and Ishii, M.: Carbon monoxide in the upper troposphere over the western Pacific between 1993 and 1996, J. Geophys. Res., 103, 1909319110, 1998.

Nara, H., Tanimoto, H., Nojiri, Y., Mukai, H., Zeng, J., Tohjima, Y., and Machida, T.: CO emissions from biomass burning in Southeast Asia in the 2006 El Niño year: shipboard and AIRS satellite observations, Environ. Chem., 8, 1-11, doi:10.1071/EN10113, 2011.

Nedelec, P., Cammas, J.-P., Thouret, V., Athier, G., Cousin, J.-M., Legrand, C., Abonnel, C., Lecoeur, F., Cayez, G., and Marizy, C.: An improved infrared carbon monoxide analyser for routine measurements aboard commercial Airbus aircraft: technical validation and first scientific results of the MOZAIC III programme, Atmos. Chem. Phys., 3, 1551-1564, doi:10.5194/acp-3-15512003, 2003.
Novelli, P. C., Collins Jr., J. E., Myers, R. C., Sachse, G. W., and Scheel, H. E.: Reevaluation of the NOAA/CMDL carbon monoxide reference scale and comparison with $\mathrm{CO}$ reference gases at NASA-Langley and Fraunhofer Institute, J. Geophys. Res., 99, 12833-12839, 1994.

Novelli, P. C., Elkins, J. M., and Steele, L. P.: The development and evaluation of a gravimetric reference scale for measurements of atmospheric carbon monoxide, J. Geophys. Res., 96, 1310913121, 1991.

Novelli, P. C., Steele, L. P., and Tans, P. P.: Mixing ratios of carbon monoxide in the troposphere, J. Geophys. Res., 97, 2073120750, 1992.

Novelli, P. C., Masarie, K. A., and Lang, P. M.: Distributions and recent changes of carbon monoxide in the lower troposphere, J. Geophys. Res., 103, 19015-19033, 1998a.

Novelli, P. C., Conners, V. S., Reichle Jr., H. G., Anderson, B. E., Brenninkmeijer, C. A. M., Brunke, E. G., Doddrige, B. G., Kirchhoff, V. W. J. H., Lam, K. S., Masarie, K. A., Matsuo, T., Parrish, D. D., Scheel, H. E., and Steele, L. P.: An internally consistent set of globally distributed atmospheric carbon monoxide mixing ratios developed using results from an intercomparison of measurements, J. Geophys. Res., 103, 19285-19293, 1998b.

Novelli, P. C., Masarie, K. A., Lang, P. M., Hall, B. D., Myers, R. C., and Elkins, J. W.: Reanalysis of tropospheric CO trends: Effects of the 1997-1998 wildfires, J. Geophys. Res., 108, 4464, doi:10.1029/2002JD003031, 2003.

Ou-Yang, C.-F., Lin, Y.-C., Lin, N.-H., Lee, C.-T., Sheu, G.-R., Kam, S.-H., and Wang, J.-L., Inter-comparison of three instruments for measuring regional background carbon monoxide, Atmos. Environ., 43, 6449-6453, 2009.

Parrish, D. D., Holloway, J. S., and Fehsenfeld, F. C.: Routine, continuous measurement of carbon monoxide with parts per billion precision, Environ. Sci. Technol., 28, 1615-1618, 1994.

Pochanart, P., Akimoto, H., Kajii, Y., and Sukasem, P.: Carbon monoxide, regional-scale transport, and biomass burning in tropical continental Southeast Asia: Observations in rural Thailand, J. Geophys. Res. 108, 4552, doi:10.1029/2002JD003360, 2003.

Sawa, Y., Tanimoto, H., Yonemura, S., Matsueda, H., Wada, A., Taguchi, S., Hayasaka, T., Tsuruta, H., Tohjima, Y., Mukai, H., Kikuchi, N., Katagiri, S., and Tsuboi, K.: Widespread pollution events of carbon monoxide observed over the western North Pacific during the East Asian Regional Experiment (EAREX) 2005 campaign, J. Geophys. Res., 112, D22S26, doi:10.1029/2006JD008055, 2007.

Takegawa, N., Kita, K., Kondo, Y., Matsumi, Y., Parrish, D. D., Holloway, J. S., Koike, M., Miyazaki, Y., Toriyama, N., Kawakami, S., and Ogawa, T.: Airborne vacuum ultraviolet resonance fluorescence instrument for in situ measurement of $\mathrm{CO}$, J. Geophys. Res., 106, 24237-24244, 2001.

Tanimoto, H., Kajii, Y., Hirokawa, J., Akimoto, H., and Minko, N. P.: The atmospheric impact of boreal forest fires in far eastern Siberia on the seasonal variation of carbon monoxide: Observations at Rishiri, a northern remote island in Japan, Geophys. Res. Lett., 27, 4073-4076, 2000.

Tanimoto, H., Sawa, Y., Matsueda, H., Yonemura, S., Wada, A., Mukai, H., Wang, T., Poon, S., Wong, A., Lee, G., Jung, J.-Y., Kim, K.-R., Lee, M., Lin, N.-H., Wang, J.-L., Ou-Yang, C.-F., and $\mathrm{Wu}, \mathrm{C} .-\mathrm{F} .:$ Evaluation of standards and methods for continuous measurements of carbon monoxide at ground-based sites in 
Asia, Pap. Meteorol. Geophys., 58, 85-93, 2007.

Tanimoto, H., Sawa, Y., Yonemura, S., Yumimoto, K., Matsueda, H., Uno, I., Hayasaka, T., Mukai, H., Tohjima, Y., Tsuboi, K., and Zhang, L.: Diagnosing recent CO emissions and ozone evolution in East Asia using coordinated surface observations, adjoint inverse modeling, and MOPITT satellite data, Atmos. Chem. Phys., 8, 3867-3880, doi:10.5194/acp-8-3867-2008, $2008 \mathrm{a}$

Tanimoto, H., Matsumoto, K., and Uematsu, M.: Ozone-CO correlations in Siberian wildfire plumes observed at Rishiri Island, SOLA, 4, 65-68, 2008b.

Tanimoto, H., Sato, K., Butler, T., Lawrence, M. G., Fisher, J. A., Kopacz, M., Yantosca, R. M., Kanaya, Y., Kato, S., Okuda, T., Tanaka, S., and Zeng, J.: Exploring CO pollution episodes observed at Rishiri Island by chemical weather simulations and AIRS satellite measurements: long-range transport of burning plumes and implications for emissions inventories, Tellus B, 61, 394-407, 2009a.

Tanimoto, H., Tohjima, Y., Mukai, H., Nara, H., and Hashimoto, S.: Anomalous geographical gap in carbon monoxide mixing ratios over Hokkaido (Japan) in summer 2004, Geochem. J. (Express Letters), 43, e23-e29, 2009b.

Warner, J., Comer, M. M., Barnet, C. D., McMillan, W. W., Wolf, W., Maddy, E., and Sachse, G.: A comparison of satellite tropospheric carbon monoxide measurements from AIRS and MOPITT during INTEX-A, J. Geophy. Res., 112, D12S17, doi:10.1029/2006JD007925, 2007.

Watanabe, K., Nojiri, Y., and Kariya, S.: Measurements of ozone concentrations on a commercial vessel in the marine boundary layer over the northern North Pacific Ocean, J. Geophys. Res., 110, D11310, doi:10.1029/2004JD005514, 2005.
Yashiro, H., Sugawara, S., Sudo, K., Aoki, S., and Nakazawa, T.: Temporal and spatial variations of carbon monoxide over the western part of the Pacific Ocean, J. Geophys. Res., 114, D08305, doi:10.1029/2008JD010876, 2009.

Yurganov, L. N., Duchatelet, P., Dzhola, A. V., Edwards, D. P., Hase, F., Kramer, I., Mahieu, E., Mellqvist, J., Notholt, J., Novelli, P. C., Rockmann, A., Scheel, H. E., Schneider, M., Schulz, A., Strandberg, A., Sussmann, R., Tanimoto, H., Velazco, V., Drummond, J. R., and Gille, J. C.: Increased Northern Hemispheric carbon monoxide burden in the troposphere in 2002 and 2003 detected from the ground and from space, Atmos. Chem. Phys., 5, 563-573, doi:10.5194/acp-5-563-2005, 2005.

Yurganov, L. N., McMillan, W. W., Dzhola, A. V., Grechko, E. I., Jones, N. B., and van der Werf, G. R.: Global AIRS and MOPITT CO measurements: Validation, comparison, and links to biomass burning variations and carbon cycle, J. Geophys. Res., 113, D09301, doi:10.1029/2007JD009229, 2008.

Zander, R., Demoulin, P., Ehhalt, D. H., Schmidt, U., and Rinsland, C. P.: Secular increase of total vertical column abundance of carbon monoxide above Central Europe since 1950, J. Geophys. Res., 94, 11021-11028, 1989.

Zellweger, C., Hüglin, C., Klausen, J., Steinbacher, M., Vollmer, M., and Buchmann, B.: Inter-comparison of four different carbon monoxide measurement techniques and evaluation of the long-term carbon monoxide time series of Jungfraujoch, Atmos. Chem. Phys., 9, 3491-3503, doi:10.5194/acp-9-3491-2009, 2009. 